\title{
Normative data of Visual Evoked Potential in children and correlation with age
}

\author{
Renu Yadav', Bishnu Hari Poudel², Nirmala Limbu³, Dilip Thakur ${ }^{4}$, Subodh Yadav ${ }^{5}$ \\ ${ }^{1}$ Lecturer, Department of Physiology, Nobel Medical College, Biratnagar, Nepal, ${ }^{2}$ Professor, Department of Basic and Clinical Physiology, \\ B.P. Koirala Institute of Health Sciences, Dharan, Nepal, ${ }^{3}$ Additional Professor, Department of Basic and Clinical Physiology, B.P. Koirala \\ Institute of Health Sciences, Dharan, Nepal, ${ }^{4}$ Associate Professor, Department of Basic and Clinical Physiology, B.P. Koirala Institute of Health \\ Sciences, Dharan, Nepal, ${ }^{5}$ Assistant Professor, Department of Anatomy, Nobel Medical College, Biratnagar, Nepal
}

\section{A B S T R A C T}

Background: Visual Evoked Potential is the assessment of the visual pathway and the visual cortex. The present study was descriptive analysis of normal VEP between the age of 6 months to 4 years of age and the determination of the neuronal development among healthy children of above age group. Materials and Methods: The study was conducted in neurological lab of BPKIHS on healthy children $(n=36)$ of well-baby clinic between the age of 0.5 to $\leq 4$ years (yr). Subjects were divided into subgroup $1(0.5$ to $\leq 2 \mathrm{yr}$ ), subgroup 2(2 to $\leq 3 \mathrm{yr}$ ) and subgroup $3(3$ to $\leq 4 \mathrm{yr}$ ). Visual stimulator provided with flash light emitting diode (LED) goggle was used to stimulate the retina and VEP recording was done. Flash VEP parameters: latencies (N90, P120) and amplitude (N90-P120) were recorded. Post hoc (Bonferroni) analysis was done for comparing VEP variables. Pearson correlation were done for VEP with respect to age. Results: VEP latencies of children, age-group 3 to $\leq 4 \mathrm{yr}$ showed significantly less $\mathrm{N90}$ latency on right eye stimulation comparing age-group 0.5 to $\leq 2 \mathrm{yr}(103.75 \pm 22.54 \mathrm{vs} .79 .09 \pm 17.77 \mathrm{~ms}, \mathrm{p}=0.012)$. P120 latency was significantly less on right eye stimulation (148.5 \pm 15.38 vs. $116.67 \pm 13.65 \mathrm{~ms}$ $p=0.001)$ and on left eye stimulation (145.91 \pm 18.11 vs. $116.67 \pm 13.65 \mathrm{~ms}, p=0.001$ ) in age-group 3 to $\leq 4 \mathrm{yr}$ children as compared to age-group 0.5 to $\leq 2 \mathrm{yr}$. Conclusion: Significant decrement of VEP latencies as age advances which explains the maturation of central nervous system and functionally approaching to adult value at around 3 to $4 \mathrm{yr}$.

Access this article online

Website:

http://nepjol.info/index.php/AJMS DOI: 10.3126/ajms.v7i2.13135 E-ISSN: 2091-0576 P-ISSN: 2467-9100

Key Words: Visual Evoked Potential, Latency, P120, N90, LED

\section{INTRODUCTION}

Historically, Richard Caton (1875) discovered evoked potentials and the electroencephalogram (EEG) at the same time. The visual evoked potentials (VEPs) result from change of brain activity following application of intermittent visual stimulus to the visual system. ${ }^{1}$ They provide a quantitative measure of the functional integrity of the visual pathways. ${ }^{2}$ Visual evoked potentials (VEPs) are massed electrical signals generated by occipital cortical areas 17,18, and 19 in response to visual stimulation. VEPs can be used to assess the integrity or maturational state of the visual pathway in infants and preverbal children. ${ }^{3}$ The VEP to flash stimulation consists of a series of negative and positive waves. The most robust components of the flash VEP are the N2 $(90 \mathrm{~ms})$ latency and P2 (120 ms) latency. ${ }^{45}$ As demonstrated by Sokol and Jones, ${ }^{6}$ the latency of the VEP matures rapidly between three and five months. Latencies of all check sizes are at adult values by age 5 , and show no significant change from then until about age 40 .

On fundoscopic examination, foveal cone photoreceptors which subserve fine detail of vision, is not mature until at least 4 years of age. ${ }^{8}$ The robust nature of the chromatic responses have allowed researchers to apply the visual evoked response (VEP) technique as a sensitive and objective measure of neural integrity in the clinic. ${ }^{9}$ VEP responses have been worked out for adult population in various studies. However, in children the recording is 
difficult and their normatives are not consistent across the studies since the normative are very necessary for diseases like birth asphyxia, cortical blindness. Objective assessment of visual pathway is done in above diseases at our center. Therefore, this study is an attempt to document VEP responses among children population from 0.5 years to 4 years. The study is also likely to produce effect of age on VEP with the time of maturation of VEP.

\section{MATERIALS AND METHODS}

The study was conducted on healthy children ( $\mathrm{n}=36$, 72 eyes) of age 6 months to 4 years old in Electrodiagnosis labs (Neurophysiology lab) of Department of Basic and Clinical Physiology, BPKIHS. It was a descriptive cross sectional study. Subjects were taken from the well-baby clinic of the Department of Paediatric and Adolescent using convenient sampling method. All the subjects were age and sex matched. Further health status was assessed by detailed medical history and physical examination (pupillary light reflex-mesopic condition). This study was conducted from 15 $5^{\text {th }}$ August, 2010 to $14^{\text {th }}$ August 2011. Recorded Variables were anthropometric variables: Age (year), height $(\mathrm{m})$, weight $(\mathrm{kg})$, body mass index $(\mathrm{kg} / \mathrm{m} 2)$ and VEP variables: N90 latency (ms) and P120 latency (ms) of right and left eye stimulation, P120 amplitude (peak to peak of N90-P120, $\mu \mathrm{V}$ ) of right and left eye stimulation. Parents were instructed to bring the child with clean scalp and hair, with adequate last night sleep (minimum 6 hours) and with light food on the day of examination. Recordings were done in morning period.

\section{Inclusion criteria}

Healthy children of either sex between the ages of 6 months to 4 years were included.

\section{Exclusion criteria}

The children with history of head injury, stroke, medical illness, using mydriatic or miotic drugs, ophthalmic health= refractive errors, ocular diseases like congenital glaucoma, cataract, uveitis and so on were excluded.

\section{Normal subjects criteria}

Children with normal general health and with normal pupillary light reflex, normal pupillary diameter, no visual complaints, no refractive errors were considered normal.

Temperature of the laboratory was maintained at $26 \pm 2^{\circ} \mathrm{C}$ by air condition. Children $\leq 4$ years were selected for flash VEP and promethazine $0.5 \mathrm{mg} / \mathrm{kg}$ body weight was administered to induce sleep.

Pre-recording and recording procedure was started by consent of the parents, health status, recording setup.
The sedation (promethazine $0.5 \mathrm{mg} / \mathrm{kg}$ body wt) of the child was done as recommended by the FDA (US Food and Drug Administration). ${ }^{10}$ Recording of VEP was done while the subject was sleeping. The scalp electrodes were placed relative to bony landmarks, in proportion to the size of the head, according to the international 10-20 system. All electrode sites were cleaned with Skinpure to clean and reduce the skin resistance. Midline-occipital (MO) electrode, the active electrode, is 5 centimetres (cms) above the inion for single channel recording. Recommended montages used were right-occipital $(\mathrm{RO})=5 \mathrm{~cm}$ right of MO (midline-occipital), left-occipital $(\mathrm{LO})=5 \mathrm{~cm}$ left of $\mathrm{MO}$ and midline-frontal (MF), the reference electrode, were placed $12 \mathrm{~cm}$ above the nasion. Earthing electrode was placed on vertex (CZ). The electrodes were filled with Nihon Kohden Elefix gel, which acts as electrical conductor and was stabilized using the electrodes in place. Then electrodes were pressed firmly on the scalp.

Recording was done by placing the electrodes on the subject's scalp according to 10/20 international system. LED goggles connected with a LED visual stimulator was put on the child's eye while the subject were sleeping and red flash of strobe light was given monocularly through goggles to both right and left eye one at a time. Signals were displayed on the monitor of Nihon Kohden machine (NM-420S; H636, Japan). The record of VEP for each eye was done from channel-1 (RO-MF) and channel-2 (LO-MF) designated as A1, A2 waves respectively. Recording was repeated for reliability with waves designated as B1, B2. The flash reversal rate was $1 / \mathrm{s}(1.0 \mathrm{~Hz} \pm 20 \%)$ for $300 \mathrm{~ms}$. The signals were averaged for 200 times. The filter was provided creating window of 1- $100 \mathrm{~Hz}$. Recordings of VEPs (Figures 1 and 2).

\section{Data analysis and statistical analysis}

Statistical analysis was done by plotting the data in Microsoft Excel. Mean, median (inter quartile

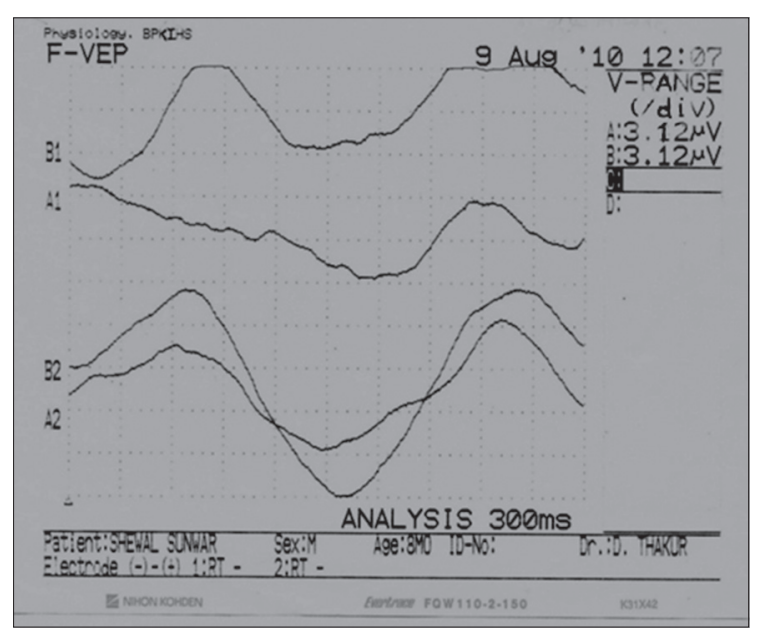

Figure 1: Flash VEP of 8 months old child (right eye) 


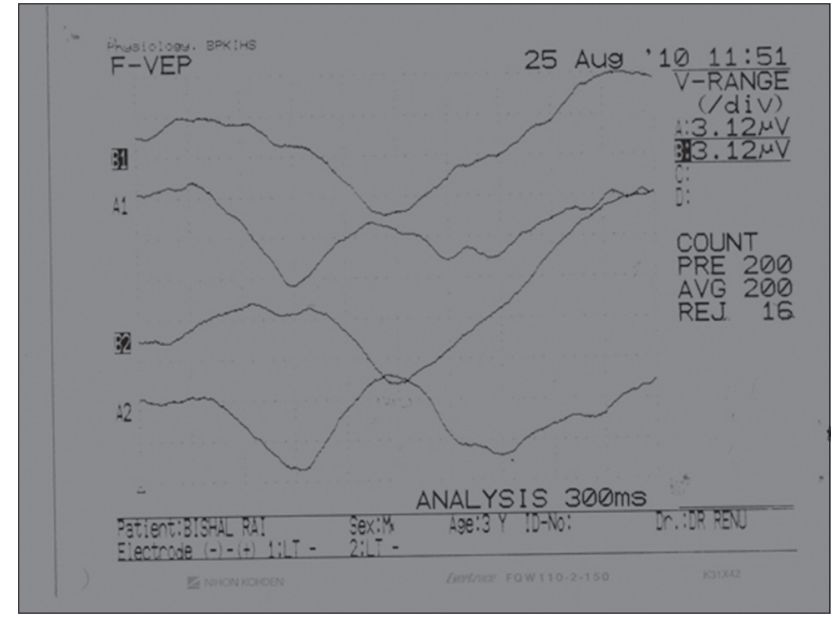

Figure 2: Flash VEP of 3 years old child (left eye)

range), mode and SD were analyzed in Excel for both anthropometric and VEP variables and normative values for each subgroups were expressed. Then all the VEP variables were entered in SPSS version 18. Post hoc (Bonferroni) analysis was done for comparing VEP variables of subgroups separately for flash group and pattern group. Pearson correlation were done for each variables of VEP with respect to age at significance value of $p<0.05$. Normative values for each subgroups are expressed in terms of mean $\pm \mathrm{SD}$.

The research proposal was submitted to the Institutional Ethical Review Board (IERB) of BPKIHS and ethical clearance was taken. Verbal and written consent was taken from the parent after giving detail information regarding the procedure.

\section{RESULTS}

Anthropometric variables were recorded and mean and standard deviation were calculated for total subjects and for subgroups (Tables 1 and 2).

Comparing flash VEP variables among subgroups of children (Table 3)

Comparing VEP latencies of children, the subgroup 3 children showed significantly less N90 latency on right eye stimulation as compared to subgroup 1 (103.75 \pm 22.54 vs. $79.09 \pm 17.77 \mathrm{~ms}, \mathrm{p}=0.012$ ). Similarly, on combining VEP N90 latencies of right and left eyes, the subgroup 3 children also showed significantly less as compared to subgroup $2(95.29 \pm 15.9$ vs. $81.39 \pm 16.36 \mathrm{~ms}, \mathrm{p}=0.03)$ and subgroup 1 (99.26 \pm 20.12 vs. $81.39 \pm 16.36 \mathrm{~ms}, \mathrm{p}=0.001)$. P120 latency on right eye stimulation (137.70 \pm 12.04 vs. $116.67 \pm 13.65 \mathrm{~ms}, \mathrm{p}=0.004)$ and on left eye stimulation $(137.18 \pm 11.7$ vs. $115.75 \pm 12.69 \mathrm{~ms}, \mathrm{p}=0.004)$ was significantly less in subgroup 3 as compared to

\begin{tabular}{|c|c|}
\hline \multirow[t]{3}{*}{ Variables } & Flash VEP \\
\hline & 0.5 to $\leq 4$ years $(n=36)$ \\
\hline & Mean $\pm S D$ \\
\hline Age (years) & $2.33 \pm 1.03$ \\
\hline Height $(m)$ & $0.88 \pm 0.11$ \\
\hline Weight (kg) & $11.09 \pm 2.21$ \\
\hline BMI $\left(\mathrm{kg} / \mathrm{m}^{2}\right)$ & $15.74 \pm 1.38$ \\
\hline
\end{tabular}

\begin{tabular}{|c|c|c|c|}
\hline \multirow[t]{3}{*}{ Variables } & \multicolumn{3}{|c|}{ Flash VEP } \\
\hline & $\begin{array}{c}\text { Subgroup } 1 \\
0.5 \text { to } \leq 2 \text { yr } \\
(n=13)\end{array}$ & $\begin{array}{c}\text { Subgroup } 2 \\
2 \text { to } \leq 3 \text { yr } \\
(n=11)\end{array}$ & $\begin{array}{c}\text { Subgroup } 3 \\
3 \text { to } \leq 4 \mathrm{yr} \\
(\mathrm{n}=12)\end{array}$ \\
\hline & \multicolumn{3}{|c|}{ Mean $\pm S D$} \\
\hline Age (years) & $1.19 \pm 0.44$ & $2.44 \pm 0.28$ & $3.48 \pm 0.29$ \\
\hline Height $(m)$ & $0.72 \pm 0.05$ & $0.86 \pm 0.04$ & $0.94 \pm 0.03$ \\
\hline Weight (kg) & $8.66 \pm 1.50$ & $12.00 \pm 0.92$ & $12.88 \pm 1.03$ \\
\hline BMI $\left(\mathrm{kg} / \mathrm{m}^{2}\right)$ & $16.60 \pm 0.98$ & $16.16 \pm 1.39$ & $14.43 \pm 0.60$ \\
\hline
\end{tabular}

subgroup 2 children. P120 latency was significantly less on right eye stimulation (148.5 \pm 15.38 vs. $116.67 \pm 13.65 \mathrm{~ms}$ $\mathrm{p}=0.001)$ and on left eye stimulation $(145.91 \pm 18.11$ vs. $116.67 \pm 13.65 \mathrm{~ms}, \mathrm{p}=0.001)$ in subgroup 3 children as compared to subgroup 1. Combining VEP P120 latencies of right and left eyes were significantly less in subgroup 3 as compared to subgroup $2(137.43 \pm 11.57$ vs. $116 \pm 12.86 \mathrm{~ms}, \mathrm{p}=0.001)$ and subgroup $1(147.26 \pm 16.4 \mathrm{vs}$. $116 \pm 12.86 \mathrm{~ms}, \mathrm{p}=0.001)$.

Pearson correlation (2-tailed) of flash VEP variables with age (Table 4)

Flash VEP N90 latency of right eye stimulation showed significant negative correlation $(r=-0.503, p=0.003)$ with respect to age. When both eyes were combined flash VEP $\mathrm{N} 90$ latencies showed more significant negative correlation $(r=-0.424, p=0.001)$ with respect to age. The VEP P120 latency of right eye $(\mathrm{r}=-0.733, \mathrm{p}=0.001)$ and left eye $(\mathrm{r}=-0.722, \mathrm{p}=0.001)$ also showed significant negative correlation with respect to age. Similarly, significant negative correlation for both eyes combined VEP P120 latency $(r=-0.728, p=0.001)$ was shown with respect to age.

\section{DISCUSSION}

The most common indication for VEP clinically is evaluation of the visual pathway function. It is part of the work-up for children with abnormal visual development or behaviour, for children or adults with visual symptoms not explained by physical examination, for cases where a psychogenic visual disorder or malingering is suspected, and in cases of optic 


\begin{tabular}{|c|c|c|c|c|c|c|c|c|}
\hline \multirow[t]{2}{*}{ Variables } & \multicolumn{2}{|c|}{ Age subgroups } & \multirow[t]{2}{*}{ Mean $\pm S D$} & \multirow{2}{*}{$\begin{array}{c}\text { Mean } \\
\text { difference }\end{array}$} & \multirow[t]{2}{*}{ SEM } & \multirow[t]{2}{*}{$P$ value } & \multicolumn{2}{|c|}{$95 \% \mathrm{Cl}$} \\
\hline & & & & & & & Lower bound & Upper bound \\
\hline \multirow[t]{4}{*}{ RLN90, ms } & 0.5 to $\leq 2 \mathrm{yr}$ & 2 to $\leq 3 \mathrm{yr}$ & $99 \pm 14.97$ & 4.75 & 8.11 & 1 & -15.81 & 25.31 \\
\hline & & 3 to $\leq 4 \mathrm{yr}$ & $79.09 \pm 17.77$ & 24.66 & 7.91 & 0.012 & 4.61 & 44.7 \\
\hline & 2 to $\leq 3 \mathrm{yr}$ & 0.5 to $\leq 2 \mathrm{yr}$ & $103.75 \pm 22.54$ & -4.75 & 8.11 & 1 & -25.31 & 15.81 \\
\hline & & 3 to $\leq 4 \mathrm{yr}$ & $79.09 \pm 17.77$ & 19.91 & 8.23 & 0.067 & -1.07 & 40.89 \\
\hline \multirow[t]{4}{*}{ LLN90, ms } & 0.5 to $\leq 2 \mathrm{yr}$ & 2 to $\leq 3 \mathrm{yr}$ & $91.91 \pm 16.66$ & 2.46 & 6.94 & 1 & -15.11 & 20.02 \\
\hline & & 3 to $\leq 4 \mathrm{yr}$ & $83.5 \pm 15.45$ & 10.86 & 6.8 & 0.36 & -6.34 & 28.06 \\
\hline & 2 to $\leq 3 \mathrm{yr}$ & 0.5 to $\leq 2 \mathrm{yr}$ & $94.36 \pm 16.78$ & -2.46 & 6.94 & 1 & -20.02 & 15.11 \\
\hline & & 3 to $\leq 4 \mathrm{yr}$ & $83.5 \pm 15.45$ & 8.41 & 6.8 & 0.676 & -8.79 & 25.61 \\
\hline \multirow[t]{4}{*}{ BLN90, ms } & 0.5 to $\leq 2 \mathrm{yr}$ & 2 to $\leq 3 \mathrm{yr}$ & $95.29 \pm 15.9$ & 3.98 & 5.32 & 1.00 & -9.10 & 17.05 \\
\hline & & 3 to $\leq 4 \mathrm{yr}$ & $81.39 \pm 16.36$ & 17.87 & 5.19 & 0.00 & 5.10 & 30.64 \\
\hline & 2 to $\leq 3 \mathrm{yr}$ & 0.5 to $\leq 2 \mathrm{yr}$ & $99.26 \pm 20.12$ & -3.98 & 5.32 & 1.00 & -17.05 & 9.10 \\
\hline & & 3 to $\leq 4 \mathrm{yr}$ & $81.39 \pm 16.36$ & 14 & 5.32 & 0.03 & 0.82 & 26.96 \\
\hline \multirow[t]{4}{*}{ RLP120, ms } & 0.5 to $\leq 2 \mathrm{yr}$ & 2 to $\leq 3 \mathrm{yr}$ & $137.70 \pm 12.04$ & 10.8 & 5.94 & 0.237 & -4.26 & 25.86 \\
\hline & & 3 to $\leq 4 \mathrm{yr}$ & $116.67 \pm 13.65$ & 32.23 & 5.79 & 0.00 & 17.55 & 46.91 \\
\hline & 2 to $\leq 3 \mathrm{yr}$ & 0.5 to $\leq 2 \mathrm{yr}$ & $148.5 \pm 15.38$ & -10.8 & 5.94 & 0.237 & -25.86 & 4.26 \\
\hline & & 3 to $\leq 4 \mathrm{yr}$ & $116.67 \pm 13.65$ & 21.43 & 6.06 & 0.004 & 6.06 & 36.79 \\
\hline \multirow[t]{4}{*}{ LLP120, ms } & 0.5 to $\leq 2 \mathrm{yr}$ & 2 to $\leq 3 \mathrm{yr}$ & $137.18 \pm 11.7$ & 8.73 & 6.14 & 0.495 & -6.81 & 24.26 \\
\hline & & 3 to $\leq 4 \mathrm{yr}$ & $115.75 \pm 12.69$ & 30.16 & 6.01 & 0.00 & 14.95 & 45.37 \\
\hline & 2 to $\leq 3 \mathrm{yr}$ & 0.5 to $\leq 2 \mathrm{yr}$ & $145.91 \pm 18.11$ & -8.73 & 6.14 & 0.495 & -24.26 & 6.81 \\
\hline & & 3 to $\leq 4 \mathrm{yr}$ & $115.75 \pm 12.69$ & 21.43 & 6.01 & 0.004 & 6.23 & 36.64 \\
\hline \multirow[t]{4}{*}{ BLP120, ms } & 0.5 to $\leq 2 \mathrm{yr}$ & 2 to $\leq 3 \mathrm{yr}$ & $137.43 \pm 11.57$ & 9.83 & 4.17 & 0.065 & -0.43 & 20.09 \\
\hline & & 3 to $\leq 4 \mathrm{yr}$ & $116 \pm 12.86$ & 31 & 4.08 & 0.00 & 21.24 & 41.28 \\
\hline & 2 to $\leq 3 \mathrm{yr}$ & 0.5 to $\leq 2 \mathrm{yr}$ & $147.26 \pm 16.4$ & -9.83 & 4.17 & 0.065 & -20.09 & 0.43 \\
\hline & & 3 to $\leq 4 \mathrm{yr}$ & $116 \pm 12.86$ & 21.4 & 4.17 & 0.00 & 11.17 & 31.69 \\
\hline \multirow[t]{4}{*}{ RAP120, $\mu \mathrm{V}$} & 0.5 to $\leq 2 \mathrm{yr}$ & 2 to $\leq 3 \mathrm{yr}$ & $3.49 \pm 1.69$ & 1.72 & 1.08 & 0.363 & -1.01 & 4.45 \\
\hline & & 3 to $\leq 4 \mathrm{yr}$ & $4.24 \pm 2.37$ & 0.97 & 1.05 & 1 & -1.69 & 3.63 \\
\hline & 2 to $\leq 3 \mathrm{yr}$ & 0.5 to $\leq 2 \mathrm{yr}$ & $5.21 \pm 3.31$ & -1.72 & 1.08 & 0.363 & -4.45 & 1.01 \\
\hline & & 3 to $\leq 4 \mathrm{yr}$ & $4.24 \pm 2.37$ & -0.75 & 1.10 & 1 & -3.54 & 2.03 \\
\hline \multirow[t]{4}{*}{ LAP120, $\mu \mathrm{V}$} & 0.5 to $\leq 2 \mathrm{yr}$ & 2 to $\leq 3 \mathrm{yr}$ & $4.34 \pm 1.5$ & 1.08 & 1.08 & 0.981 & -1.66 & 3.81 \\
\hline & & 3 to $\leq 4 \mathrm{yr}$ & $4.48 \pm 3.07$ & 0.94 & 1.06 & 1 & -1.74 & 3.62 \\
\hline & 2 to $\leq 3 \mathrm{yr}$ & 0.5 to $\leq 2 \mathrm{yr}$ & $5.41 \pm 2.69$ & -1.08 & 1.08 & 0.981 & -3.81 & 1.66 \\
\hline & & 3 to $\leq 4 \mathrm{yr}$ & $4.48 \pm 3.07$ & -0.14 & 1.06 & 1 & -2.82 & 2.54 \\
\hline \multirow{4}{*}{ BAP120, $\mu \mathrm{V}$} & 0.5 to $\leq 2 \mathrm{yr}$ & 2 to $\leq 3 \mathrm{yr}$ & $3.93 \pm 1.61$ & 1.37 & 0.75 & 0.21 & -0.47 & 3.21 \\
\hline & & 3 to $\leq 4 \mathrm{yr}$ & $4.36 \pm 2.7$ & 0.94 & 0.73 & 0.61 & -0.85 & 2.74 \\
\hline & 2 to $\leq 3 \mathrm{yr}$ & 0.5 to $\leq 2 \mathrm{yr}$ & $5.31 \pm 2.87$ & -1.37 & 0.75 & 0.21 & -3.21 & 0.47 \\
\hline & & 3 to $\leq 4 \mathrm{yr}$ & $4.36 \pm 2.7$ & -0.43 & 0.75 & 1.00 & -2.27 & 1.41 \\
\hline
\end{tabular}

RLN9o=Flash VEP Ngo latency of right eye; LLN9o=Flash VEP Ngo latency of left eye; BLN9o=Combining NgoVEP latencies of both eyes; RLP120=Flash VEP P120 latency of right eye; LLP120=Flash VEP P 120 latency of left eye; BLP120=Combining $P_{120}$ VEP latencies of both eyes; RAP $120=F l a s h$ VEP $P_{12} 2$ amplitude of right eye; $L A P 120=F l a s h$ VEP $P_{120}$ amplitude of left eye; $B A P 120=C o m b i n i n g ~ P 120$ VEP amplitudes of both eyes; $P$ value $<0.05$, statistically significant

\begin{tabular}{|c|c|c|c|}
\hline \multirow[t]{2}{*}{ Variables } & \multirow[t]{2}{*}{$\begin{array}{l}\text { Eyes } \\
\text { stimulation }\end{array}$} & \multicolumn{2}{|c|}{$\begin{array}{c}\text { Flash groups } \\
(0.5 \text { years to } \leq 4 \text { years) }\end{array}$} \\
\hline & & $\begin{array}{l}\text { Pearson } \\
\text { correlation } \\
\text { ( } r \text { value) }\end{array}$ & $\begin{array}{l}\text { Significance } \\
\text { ( } p \text { value) }\end{array}$ \\
\hline \multirow[t]{3}{*}{ LN90 (ms) } & Right $(n=36)$ & -0.503 & $0.003^{* *}$ \\
\hline & Left $(n=36)$ & -0.334 & 0.054 \\
\hline & $\begin{array}{l}\text { Both eyes } \\
\text { combined }(n=66)\end{array}$ & -0.424 & $0.001^{* *}$ \\
\hline \multirow[t]{3}{*}{ LP120 (ms) } & Right $(n=36)$ & -0.733 & $0.001^{* *}$ \\
\hline & Left $(n=36)$ & -0.722 & $0.001^{* *}$ \\
\hline & $\begin{array}{l}\text { Both eyes } \\
\text { combined }(n=66)\end{array}$ & -0.728 & $0.001^{* *}$ \\
\hline \multirow[t]{3}{*}{ AP120 $(\mu \mathrm{V})$} & Right $(n=36)$ & -0.226 & 0.206 \\
\hline & Left $(n=36)$ & -0.151 & 0.393 \\
\hline & $\begin{array}{l}\text { Both eyes } \\
\text { combined }(n=66)\end{array}$ & -0.184 & 0.136 \\
\hline
\end{tabular}

LN9o=Flash VEP Ngo latency; LP120=Flash VEP P120 latency; AP120=Flash VEP $\mathrm{P} 120$ amplitude. $\mathrm{P}$ value $<0.05$, statistically significant nerve disease, especially inflammation. Our centre, Basic and Clinical Physiology of BPKIHS is regularly reporting the cases of Birth Asphyxia, Cortical Blindness, etc. Apart from these established indications, some centres also use specialised VEP methods for the objective assessment of visual acuity according to Tyler et al. $1979 .{ }^{11}$

In our study, we have subjected flash stimulus to 0.5 to 4 years children. These children were divided into subgroups 1 ( 0.5 to $\leq 2$ years, $\mathrm{n}=13), 2$ ( 2 to $\leq 3$ years, $\mathrm{n}=11$ ), and 3 ( 3 to $\leq 4$ years, $\mathrm{n}=12$ ) according to their age. The study showed the continuation of maturation of VEP around 4 years. Comparing VEP latencies of children, age group 3-4 yr children showed significantly less N90 latency on right eye stimulation as compared to age-group $0.5-2$ yr (103.75 \pm 22.54 vs. $79.09 \pm 17.77 \mathrm{~ms}, \mathrm{p}=0.012)$. Amplitude also showed decreasing trend in our study in the age group 0.5 year to $\leq 4$ years. Since the study showed 
the decreasing trend of the latency upto 4 yrs supporting the incomplete VEP maturation. Lippe et $\mathrm{al}^{12}$ have found similar result on VEP analysis of sixty-three infants aged 27 days to 5.5 years comparing among six age subgroups. All components follow a significant decrease in latency with age, reaching their adult values around 7-12 months. Langrova et $\mathrm{a}^{13}$ have mentioned that maturation of the flash VEPs and pattern-related VEPs finish by 6 years of age.

In our study (check size 66'), latency has not reached to adult level up to 4 years among flash subgroups children. Mean latencies and amplitudes obtained for mean age (each subgroup) in given stimulus conditions showed age related decline from 6 months to 4 years. N90 latency showed significant negative correlation with age for right eye $(\mathrm{r}=-0.503, \mathrm{p}=0.003)$ and both eyes combined $(\mathrm{r}=-0.424$, $\mathrm{p}=0.001)$. P120 latency also showed significant decreasing trend $(r=-0.728, p=0.001)$ for both eyes combined. The study of Moskowitz et $\mathrm{al}^{14}$ have found that P1 (first positive wave) latency decreases rapidly during the first year of life for both large and small checks and that the time course of the latency change differs as a function of check size. VEPs to large checks attain adult-like P1 latency values by about 1 year of age, while the P1 latency of VEPs to small checks still not reached adult levels by 5 years of age. It was agreed that latencies of pattern reversal VEPs to small checks ( $<20$ '; by 9 years) reach mature levels at a slower rate which supports our study.

Our results are consistent with the results of Jelka $\mathrm{B}^{15}$ using pattern reversal and pattern onset stimulus. Maturational changes were rapid in infants and gradual in school children. Age-related changes in pattern electroretinograms in infants was seen as a decrease in latency. Pattern VEP showed agerelated decrease in latency, and increase in amplitude and the development of the waveform as seen in our results. In schoolchildren, pattern VEP changes showed more gradual decrease in latency suggest that the electrophysiological maturation proceeds until adulthood. Mean latencies and amplitudes obtained for mean age (each subgroup) in given stimulus conditions showed age related decline from 6 months to 4 years in our study. Normative values in infants and schoolchildren are an important factor in differentiating maturation of the visual system from pathological processes.

Concluding the various findings, it has been found small variations due to the difference of the stimulus. Most of the studies including the present one showed the results that the maturation of the visual pathway is around 4 years.

\section{ACKNOWLEDGEMENTS}

I would like to take this opportunity to express my profound gratitude and appreciation to my respected teacher and guide Dr. Bishnu Hari Paudel, Professor and Head, Department of Basic and Clinical Physiology, BPKIHS for his never ending generous help, keen observation, valuable suggestions and constant encouragement. Words would not suffice to express my thanks to him. I will always remain indebted to him.

\section{REFERENCES}

1. Shagass C. Evoked brain potential in man. Biological foundations of psychiatry. New York: Raven Press 1976; 199-253.

2. Celesia GG. Anatomy and physiology of visual evoked potential and electroretinograms. Neurol Clin1988; 6:657-665.

3. Aminoff MJ. VEP, Electrodiagnosis in clinical neurology. $4^{\text {th }}$ ed. London: Churchill Livingstone 1999; 421-449.

4. Spekreijse H, Dagnelie G, Maier J and Regan D. Flicker and movement constituents of the pattern reversal response. Vision Res 1995; 25:1297.

5. Dagnalie G, De Vries MJ, Maier J and Spekreijse H. Pattern reversal stimuli, motion or contrast? Doc Ophthalmol 1986; $61: 343$.

6. Sokol $S$ and Moskowitz A. Implicit time of pattern evoked potential in infants. An index of maturation of spatial vision. Vision Res 1979; 19: 747-755.

7. Cohn N, Kircher J, Emmerson R and Dustman R. Pattern reversal evoked potential. Age sex and hemisphere asymmetry. Electroencephalogram Clin Neurophysiol 1985; 62:399-405.

8. Hendrickson A. Development of the primate retina. In Simons K ed. Early visual development, Normal and abnormal. Oxford University Press, New York1993; 287.

9. Crognale MA. Development, maturation, and aging of chromatic visual pathways. VEP results 2002; 2:438-450.

10. WHO drug information, Health Science Authority Product Safety Alert 2006; 20:1-58. http://www.hsa.gov.sg/cda/safetyalert.

11. Tyler CW, Apkarian P, Levi DM and Nakayama K. Rapid assessment of visual function: an electronic sweep technique for the pattern visual evoked potential. Investigative Ophthalmology \& Visual Science 1979; 18: 703-713.

12. LippéS, Roy MS, Perchet $C$ and Lassonde M. Electrophysiological markers of visuocortical development. Life sciences and medicine and cerebral cortex 2007; 17: 100-107.

13. Langrova J, Kuba M, Kremlacek J, Kubova $Z$ and Vit F. Motion-onset VEPs reflect long maturation and early aging of visual motion-processing system. Vision Research 2006; 46: 536-544.

14. Moskowitz A and Sokol S. Developmental changes in the human visual system as reflected by the latency of the pattern reversal VEP. EEG Clin Neurophysiol 1983; 56:1-15.

15. Brecelj J. From immature to mature pattern ERG and VEP. Doc Ophthalmol 2003; 107:215-224.

\footnotetext{
Authors Contribution:

RY - Concept, design, literature review, analysis and preparation of manuscript; BHP - Help in concept and analysis of the study; NL - Literature search and preparing first draft of manuscript; DT - Data collection; SY - Critical revision of manuscript.
}

Source of Support: Nil, Conflict of Interest: None declared. 